\title{
Otodectic and bacterial etiology of feline otitis externa in Tripoli, Libya
}

\author{
Murad A. Hiblu', Omar M. Ellraiss², Elfurgani S. Karim³, Rabia A. Elmishri³ ${ }^{3}$ Enass M. Duro \\ Abdulnasser A. Altaeb ${ }^{1}$ and Emad M. Bennour ${ }^{1}$ \\ ${ }^{1}$ Department of Internal Medicine, Faculty of Veterinary Medicine, University of Tripoli, Tripoli, Libya \\ ${ }^{2}$ Al-Helal Al-Azraq Clinic, Animal Health Department - Tripoli, Ministry of Agriculture and Animal Wealth, Tripoli, Libya \\ ${ }^{3}$ Microbiology Lab Department, National Center for Animal Health, Tripoli, Libya \\ ${ }^{4}$ School of Health and Related Research, University of Sheffield, Sheffield, UK
}

\begin{abstract}
Background: Feline otitis externa is a dermatological disorder with a multifactorial complex etiology.

Aim: This study aimed to investigate the prevalence of different etiological agents, particularly the parasitic and bacterial, responsible for the cases of feline otitis externa in Tripoli, Libya, and to assess the antimicrobial susceptibility of the bacterial isolates from those cases.

Methods: Cerumen and otic discharges of the suspected cats were collected for parasite detection and bacterial culture. Kirby-Bauer's disk diffusion method was used for antimicrobial susceptibility testing.

Results: The results showed that otodectic mites and bacterial causes were equally the most prevalent in those cases, with a prevalence of $47.1 \%$ each. Otodectes cynotis infestation was more frequently bilateral and severe. Staphylococcus spp. were the most prevalent among bacterial causes (75\%), followed by Proteus spp. (16.6\%) and Pseudomonas spp. (8.4\%). Norfloxacin and gentamicin were the most effective antimicrobials against bacterial isolates, as they were effective against $83.3 \%$ and $70.8 \%$ of isolates, respectively.

Conclusion: Otodectes cynotis infestation and staphylococcal infections constituted the most common etiology of feline otitis externa in Tripoli, Libya, and norfloxacin represented a cogent antibacterial for the treatment of otitis externa.
\end{abstract}

Keywords: Antimicrobial susceptibility, Bacteria, Cats, Ear mite, Otitis externa.

\section{Introduction}

Feline otitis is etiologically a complex disease, which can be clinically challenging (Shokri et al., 2010; Kennis, 2013). Otitis externa is the inflammation of the external ear canal, outside of the tympanic membrane, and sometimes the pinna (Rosser et al., 2004; Kennis, 2013; Bollez et al., 2018). This dermatological disorder may be acute or chronic (Moriello, 2013).

Causes of otitis externa could be primary or secondary, with a variety of predisposing and perpetuating factors that contribute to/or promote the disease. Collectively, these causes and factors are referred to as the primary secondary predisposing perpetuating (PSPP) classification system (Jacobson, 2002; Moriello, 2013). Primary causes of otitis externa affect normal ear and include foreign bodies, parasites, fungi (e.g., Aspergillus, Sporothrix, and Stephanoascus), allergy, autoimmune and immune-mediated diseases, endocrine and glandular disorders, viruses, and miscellaneous (Dion and Speckmann, 1978; Jacobson, 2002; Shokri et al., 2010; Kennis, 2013; Moriello, 2013; dos Reis Gomes et al., 2014; Mascarenhas et al., 2019).

These primary causes are usually unnoticed clinically, but they alter the ear environment and, therefore, facilitate secondary infections. Secondary causes of otitis externa affect abnormal ear and include bacteria, fungi, medication reactions, over-cleaning, and yeast overgrowth (Crespo et al., 2000; Jacobson, 2002; Hariharan et al., 2006; Shokri et al., 2010; Kennis, 2013; Moriello, 2013; Kittl et al., 2018).

Predisposing factors contributing to otitis externa include excessive local moisture and increased $\mathrm{pH}$, trauma, obstruction of the ear canal, primary otitis media, systemic diseases, and treatment effects (Jacobson, 2002; Moriello, 2013). Perpetuating factors include changes in the ear epithelium, ear canal edema and stenosis, tympanic membrane dilatation and rupture, and sebaceous gland hyperplasia (Jacobson, 2002; Moriello, 2013).

Clinically, otitis externa can be unilateral or bilateral, acute or chronic and mild to severe. The common clinical findings of otitis externa include headshaking, aural pruritus, pain, and discomfort upon ear palpation and swelling, fibrosis, or calcification of the ear canal or pinna (Jacobson, 2002; Moriello, 2013).

Because of the diversity of the PSPP system contributing to the etiology and pathogenesis of otitis externa, the successful treatment depends on the identification of the causes and factors implicated in a given case. Accordingly, the treatment protocol of otitis externa may include ear cleaning, management of pain 
and pruritus, and the administration of topical and/or systemic drugs. Generally, drugs used for the treatment of otitis externa include ceruminolytic solutions, analgesics, glucocorticoids, anti-parasitics, antibiotics, and antifungals (Hariharan et al., 2006; Roy et al., 2011; Moriello, 2013; Momota et al., 2016; Yang and Huang, 2016; Arisov et al., 2020).

The prognosis of otitis externa is variable. Cases of feline otitis externa may be amenable, nonrecurring, and curable with treatment for weeks or via surgery. However, long-term management, which may take months, could be required in other recurrent cases that are unresponsive to routine therapy (Jacobson, 2002; Moriello, 2013).

Antimicrobial-resistant strains of Staphylococcus and Pseudomonas otitis have been emerged as frustrating and difficult causes of otitis because of the development of resistance to most common antibiotics (Hariharan et al., 2006; Qekwana et al., 2017). Antimicrobial-resistant strains are capable of causing a large nosocomial outbreak that is difficult to control in veterinary healthcare facilities (Gronthal et al., 2014). Feline otitis externa is a multifactorial dermatological disorder that has not been fully elucidated and studies about it are lacking (Perego et al., 2014; Bollez et al., 2018; Tyler et al., 2019). In this regard, the objective of this study was to investigate the prevalence of different etiological agents responsible for feline otitis externa in Tripoli, Libya, particularly the bacterial and parasitic organisms, and to assess the antimicrobial susceptibility of bacterial isolates from such cases.

\section{Materials and Methods}

\section{Clinical examination and sampling}

Fifty-one cats presented to Al-Helal Al-Azraq central veterinary clinic in Tripoli, Libya, during the period from August 2016 to November 2019, with a complain of discomfort, otic pruritus, head rubbing, headshaking, ear scratching, and sometimes a head tilt, with the affected ear evidently tilted down. A thorough clinical examination of the ear pinnae and canals was carried out with the help of otoscope whenever possible.

Samples of maximum possible quantity of cerumen and discharges were collected from the affected ear(s) for further microscopic ear mite detection, as well as for bacterial isolation and antimicrobial susceptibility testing. Cytology sterile ear swabs, for bacterial cultures, were taken from the horizontal ear canal before otoscopy was completed and before any cleaning process. Collected samples were transported immediately to the lab for culturing.

\section{Laboratory examination}

\section{Ear mite examination}

Smears were made by combining cerumen and otic discharge with a small quantity of mineral oil on a microscopic glass slide. A clean glass coverslip was put on the top surface of the smear and examined microscopically (40X and 100X magnification) on the same day, for the presence of adult mites, nymphs, larvae, or ova. The total mite number was determined and ear mite genus was identified through morphological characteristics. The severity of infestation was scored according to the adult mite count on the smear; as mild (less than three mites), intermediate (three to five mites) or severe (more than five mites).

\section{Bacteriological culture}

The collected specimens were cultured onto 5\% sheep blood agar and MacConkey agar (Oxoid, UK). Plates were incubated aerobically at $37^{\circ} \mathrm{C}$ for $24-48$ hours. Subculture plates were made from primary cultures. Bacterial growth on culture plates were identified using standard biochemical tests as previously described (Markey et al., 2013). API bacterial identification strips (BioMérieux, Marcy L'Etoile, France) were also used for the identification of isolates.

\section{Antimicrobial susceptibility testing}

For investigating the susceptibility of bacterial isolates to antibiotics, isolates were subjected to KirbyBauer's disk diffusion method. Briefly, antibiotic disks including norfloxacin $(10 \mu \mathrm{g})$, gentamicin (30 $\mu \mathrm{g})$, oxytetracycline $(30 \mu \mathrm{g})$, amoxicillin $(30 \mu \mathrm{g})$, penicillin (10 units), and colistin $(10 \mu \mathrm{g})$ were diffused onto Mueller-Hinton agar (Oxoid, UK) culture plates seeded with the bacterium to be tested. The plates were then incubated at $37^{\circ} \mathrm{C}$ for $18-24$ hours. The inhibition zones of all drugs were interpreted as described previously (Markey et al., 2013).

\section{Statistical analysis}

Collected data were analyzed using the Statistical Package for Social Science (SPSS) v20 software (IBM). Frequency and percentage were used to describe the data.

\section{Ethical approval}

This study was approved by the Department of Internal Medicine of the Faculty of Veterinary Medicine at the University of Tripoli, Libya. Clinical examination and sampling procedures were carried out as per animal welfare protocols.

\section{Results}

\section{General characteristics of feline subjects}

In total, 51 cats (aged 2-48 months; mean \pm SD of $15.26 \pm 13.32$ months) showing signs of otitis externa were included in the current study. Of these, $41.2 \%$ ( $n$ $=21)$ were males and $58.8 \%(n=30)$ were females (Table 1). Also, 51\% $(n=26)$ of the cases were local breed (Table 2). Other breeds were Persian, Mixed, Siamese, and Himalayan, which constituted 17.6\% ( $n$ $=9), 15.7 \%(n=8), 11.8 \%(n=6)$, and $3.9 \%(n=2)$ of the cases, respectively (Table 2).

Common causes of feline otitis externa in Tripoli, Libya Otitis externa is multifactorial with a diversified PSPP classification system. The aim of this study was to determine the causes responsible for otitis externa in cats in Tripoli, Libya, particularly those of parasitic and bacterial origin. The results revealed that the parasitic 
and bacterial causes were equally the most prevalent (Table 3), with a prevalence of $47.1 \%(24 / 51)$ each. Otodectes cynotis was diagnosed alone in $25.5 \%$ $(13 / 51)$ of cats with otitis externa and in $21.6 \%(11 / 51)$ of the cases together with bacterial infection (Table 3). Similarly, feline otitis externa was exclusively of bacterial origin in $25.5 \%(13 / 51)$ of the cases and together with $O$. cynotis in $21.6 \%(11 / 51)$ of the cases (Table 3$)$. The results also revealed that $27.4 \%(14 / 51)$ of otitis externa cases were attributed to other causes, viz foreign body, ringworm, and Malassezia yeast (Table 3).

\section{Frequency and severity of otodectic feline otitis externa} in Tripoli, Libya

In order to focus more clinically on feline otodectic otitis externa, some aspects like ear involvement and degree of infestation were investigated. In terms of ear involvement, O. cynotis more frequently infested both ears, as it was bilateral in $75.0 \%(18 / 24)$ of the cases and unilateral in $25.0 \%(6 / 24)$ of the cases: $16.7 \%$ $(4 / 24)$ in the left ear and $8.3 \%(2 / 24)$ in the right ear (Table 4).

Concerning the degree of infestation, otodectic feline otitis externa cases were mostly seriously affected. O. cynotis infestation was severe in $70.8 \%(18 / 24)$,

Table 1. Gender-wise distribution of cats with otitis externa.

\begin{tabular}{lcc}
\hline Gender & Number & \% \\
\hline Male & 21 & 41.2 \\
Female & 30 & 58.8 \\
Total & 51 & 100.0 \\
\hline
\end{tabular}

Table 2. Breed-wise distribution of cats with otitis externa.

\begin{tabular}{lcc}
\hline Breed & Number & \% \\
\hline Local & 26 & 51.0 \\
Persian & 9 & 17.6 \\
Mixed & 8 & 15.7 \\
Siamese & 6 & 11.8 \\
Himalayan & 2 & 3.9 \\
Total & 51 & 100.0 \\
\hline
\end{tabular}

Table 3. Epidemiology of feline otitis externa in Tripoli, Libya.

\begin{tabular}{lcc}
\hline Cause of otitis external & Number & $\mathbf{\%}$ \\
\hline O. cynotis & 13 & 25.5 \\
\hline Bacteria & 13 & 25.5 \\
\hline Both mite and bacteria & 11 & 21.6 \\
\hline Others & 14 & 27.4 \\
\hline Total & 51 & 100.0 \\
\hline
\end{tabular}

intermediate in $25.0 \%(6 / 24)$, and mild in $4.2 \%(1 / 24)$ of cases (Table 4).

Prevalence of bacterial organisms associated with feline otitis externa in Tripoli, Libya

Bacteria represent an important element in the PSPP classification system of otitis externa. One part of the study was to determine the prevalence of bacterial organisms isolated from cases of feline otitis externa in Tripoli, Libya. The results showed that Staphylococcus spp. were the most prevalent among bacterial causes, with a prevalence of $35.3 \%(18 / 51)$ among all feline otitis externa cases and 75\% (18/24) among bacterial feline otitis externa cases (Table 5). Staphylococcus spp. were followed by the Proteus spp., with a prevalence of $7.8 \%(4 / 51)$ among all feline otitis externa cases, and $16.6 \%$ (4/24) among bacterial feline otitis externa cases (Table 5). Pseudomonas spp. were the least isolated, with a prevalence of $3.9 \%(2 / 51)$ among all feline otitis externa cases and $8.4 \%(2 / 24)$ among bacterial feline otitis externa cases (Table 5).

Antimicrobial susceptibility of bacteria isolated from feline otitis externa cases in Tripoli, Libya

Effective treatment of cases with bacterial otitis externa requires antimicrobial therapy. Recently, many antibiotic-resistant bacterial strains have emerged. Therefore, an antimicrobial susceptibility assay was carried out for determining the antibiotic(s) of choice for the diseased cats.

Table 4. Distribution and severity of feline otodectic otitis externa in Tripoli, Libya.

\begin{tabular}{llll}
\hline Ear Mite & & Number & \% \\
\hline \multirow{4}{*}{ Ear involved } & $\mathrm{R}$ & 2 & 8.3 \\
& $\mathrm{~L}$ & 4 & 16.7 \\
& $\mathrm{R}+\mathrm{L}$ & 18 & 75.0 \\
& Total & 24 & 100.0 \\
& Mild & 1 & 4.2 \\
Degree of severity & Intermediate & 6 & 25.0 \\
& Severe & 17 & 70.8 \\
& Total & 24 & 100.0 \\
\hline
\end{tabular}

Table 5. Prevalence of bacterial organisms isolated from cats with otitis externa in Tripoli, Libya

\begin{tabular}{lcccc}
\hline \multirow{2}{*}{ Isolated Bacteria } & \multicolumn{2}{c}{ Among all } & \multicolumn{2}{c}{ Among bacteria } \\
\cline { 2 - 5 } & Number & $\mathbf{\%}$ & Number & $\mathbf{\%}$ \\
\hline Staphylococcus spp. & 18 & 35.3 & 18 & 75.0 \\
\hline Proteus spp. & 4 & 7.8 & 4 & 16.6 \\
\hline Pseudomonas spp. & 2 & 3.9 & 2 & 8.4 \\
No bacteria & 27 & 52.9 & IIII & IIII \\
Total & 51 & 100.0 & 24 & 100.0 \\
\hline
\end{tabular}


Table 6. Antibiogram profile of bacteria isolated from cats with otitis externa in Tripoli, Libya.

\begin{tabular}{lccccccc}
\hline & \multicolumn{2}{c}{ Staphylococcus spp. } & \multicolumn{2}{c}{ Pseudomonas spp. } & \multicolumn{2}{c}{ Proteus spp. } & \multirow{2}{*}{ Total } \\
\cline { 2 - 6 } & Number $^{\mathrm{a}}$ & $\%^{\mathrm{b}}$ & Number & $\%$ & Number & $\%$ & \\
\hline Norfloxacin & $16(2)$ & 80.0 & $2(0)$ & 10.0 & $2(2)$ & 10.0 & 20 \\
Gentamicin & $12(6)$ & 70.6 & $2(0)$ & 11.8 & $3(1)$ & 17.6 & 17 \\
Oxytetracycline & $5(13)$ & 62.5 & $1(1)$ & 12.5 & $2(2)$ & 25.0 & 8 \\
Amoxicillin & $1(17)$ & 33.3 & $0(2)$ & 0.0 & $2(2)$ & 66.7 & 3 \\
Penicillin & $3(15)$ & 100.0 & $0(2)$ & 0.0 & $0(4)$ & 0.0 & 3 \\
Colistin & $0(18)$ & 0.0 & $1(1)$ & 100.0 & $0(4)$ & 0.0 & 1 \\
\hline
\end{tabular}

${ }^{\text {aS }}$ Susceptible (resistant).

${ }^{\mathrm{b}}$ Among the total isolates susceptible to the respective antibiotic.

Table 7. Antimicrobial susceptibility of bacteria isolated from feline otitis externa cases in Tripoli, Libya.

\begin{tabular}{|c|c|c|c|c|c|}
\hline & & Staphylococcus spp. & Pseudomonas spp. & Proteus spp. & Total \\
\hline & & Number $\left(\% 0^{a}\right)$ & Number (\%) & Number (\%) & Number (\%) \\
\hline \multirow{2}{*}{ Norfloxacin } & + & $1(5.0)$ & $0(0.0)$ & $0(0.0)$ & $1(5.0)$ \\
\hline & ++ & $15(75.0)$ & $2(10.0)$ & $2(10.0)$ & $19(95.0)$ \\
\hline \multirow{2}{*}{ Gentamicin } & + & $10(58.8)$ & $2(11.8)$ & $2(11.8)$ & $14(82.4)$ \\
\hline & ++ & $2(11.8)$ & $0(0.0)$ & $1(5.9)$ & $3(17.6)$ \\
\hline \multirow{2}{*}{ Oxytetracycline } & + & $4(50.0)$ & $1(12.5)$ & $2(25.0)$ & $7(87.5)$ \\
\hline & +++ & $1(12.5)$ & $0(0.0)$ & $0(0.0)$ & $1(12.5)$ \\
\hline Amoxicillin & + & $1(33.3)$ & $0(0.0)$ & $2(66.7)$ & $3(100.0)$ \\
\hline \multirow{2}{*}{ Penicillin } & + & $1(33.3)$ & $0(0.0)$ & $0(0.0)$ & $1(33.3)$ \\
\hline & ++ & $2(66.7)$ & $0(0.0)$ & $0(0.0)$ & $2(66.7)$ \\
\hline Colistin & + & $0(0.0)$ & $1(100.0)$ & $0(0.0)$ & $1(100.0)$ \\
\hline
\end{tabular}

$+=$ Mildly susceptible; $++=$ Intermediately susceptible; $+++=$ Highly susceptible.

${ }^{a}$ Among the total isolates susceptible to the respective antibiotic.

The results showed that norfloxacin was the most effective antimicrobial against bacterial isolates $(83.3 \%, 20 / 24)$ (Table 6). Staphylococci isolates were most susceptible to enrofloxacin, $(80 \%, 16 / 20)$, whereas Pseudomonas spp. and Proteus spp. isolates constituted only $10 \%(2 / 20)$ each (Table 6). The majority of isolates, $95 \%(19 / 20)$, were intermediately susceptible to norfloxacin (Table 7).

Gentamicin was following enrofloxacin in effectiveness, as $70.8 \%(17 / 27)$ of bacterial isolates were susceptible to it (Table 6). Furthermore, staphylococcal isolates were the most susceptible to gentamicin (70.6\%, 12/17), followed by Proteus spp. (17.6\%, 3/17) and then by Pseudomonas spp. (11.8\%, 2/17) (Table 6). The majority of isolates $(82.4 \%, 14 / 17)$ were mildly susceptible to gentamicin (Table 7).

Oxytetracycline was less effective against $33.3 \%(n=$ 8) of bacterial isolates when compared to norfloxacin and gentamicin (Table 6). Staphylococci species isolates were the most susceptible to oxytetracycline $(62.5 \%, 5 / 8)$, followed by Proteus spp. $(25 \%, 2 / 8)$ and
Pseudomonas spp. (12.5\%, 1/8) (Table 6). The majority of these bacterial isolates $(87.5 \%, 7 / 8)$ were mildly susceptible to oxytetracycline (Table 7).

The results also showed that amoxicillin, penicillin, and colistin were the least effective antibiotics against the bacterial isolates with a percentage of $12.5 \%(3 / 24)$, $12.5 \%(3 / 24)$ and $4.1 \%(1 / 24)$, respectively (Table 6$)$. Amoxicillin exhibited a mild effect mostly against some Proteus isolates $(66.7 \%, 2 / 3)$, whereas penicillin showed an intermediate effect against staphylococcal isolates $(100 \%, 3 / 3)$ (Tables 6 and 7). Colistin was mildly effective only against Pseudomonas spp. isolate $(100 \%, 1 / 1)$ (Tables 6 and 7).

In terms of bacterial isolates susceptibility, Staphylococcus isolates were most susceptible to norfloxacin $(88.8 \%, 16 / 18)$, followed by gentamicin $(66.6 \%, 12 / 18)$, oxytetracycline $(27.7 \%, 5 / 18)$, penicillin $(16.6 \%, 3 / 18)$, and amoxicillin $(5.5 \%, 1 / 18)$, but resistant to colistin (Table 6). Proteus isolates were more susceptible to gentamicin $(75 \%, 3 / 4)$, followed by norfloxacin, oxytetracycline, and amoxicillin $(50 \%$, 
2/4 each), but resistant to penicillin and colistin (Table 6). However, Pseudomonas isolates were highly susceptible to norfloxacin and gentamicin $(100 \%, 2 / 2$ each) (Table 6).

\section{Discussion}

Feline otitis externa is a dermatological disorder with a complex etiology. It is multifactorial with a diversified PSPP classification system. In this context, this study was conducted to investigate the prevalence of different etiological agents, in particular the parasitic and bacterial organisms, responsible for the cases of feline otitis externa in Tripoli, Libya, and to assess the antimicrobial susceptibility of the bacterial isolates.

The current study involved 51 cats presented with a history and clinical findings compatible with otitis externa irrespective of the gender, age, and breed.

The results revealed that most of feline otitis externa in Tripoli were due to otodectic mites and bacterial causes with a prevalence of $47.1 \%$ each. In addition, $25.5 \%$ of feline otitis externa was caused by either $O$. cynotis or bacterial infection. However, co-infection with $O$. cynotis and bacteria was seen in $21.6 \%$ of cases. The remaining cases of otitis externa $(27.4 \%)$ were due to other causes. These findings are in agreement with other studies' results (Griffin, 1993; Topala et al., 2007; Roy et al., 2011; Perego et al., 2014; Harvey and Paterson, 2014; Nardoni et al., 2014; Yang and Huang, 2016), which reported that otodectic otitis externa was prevalent in more than $50 \%$ of cats with otitis externa. These observations are also in the line with the findings of Perego et al. (2014) who reported that bacterial causes were highly prevalent $(>70 \%)$ in feline otitis externa cases. However, other studies reported a low prevalence of otodectic and bacterial otitis externa, but a more prevalent Malassezia species microorganism in otitis externa or healthy subjects (Bollez et al., 2018; Tyler et al., 2019).

In the present study, otodectic otitis was more frequently bilateral and severe. Generally, O. cynotis is considered to be very contagious (Roy et al., 2011). Roy et al. (2011) and Sotiraki et al. (2001) reported aural pruritus and abnormal auricular secretions in $41.5 \%$ and $85.4 \%$ of infested cats, respectively. In addition, $O$. cynotis can cause a hypersensitivity reaction in some individuals (Powell et al., 1980; Roy et al., 2011). Furthermore, the severity of otodectic otitis in the current study could be also attributed to the delayed presentation of the cases and negligence of therapy.

The results also showed that Staphylococcus spp. infection was the most prevalent among the causes of bacterial otitis externa with a prevalence of $35.3 \%$ (75\% of bacterial otitis externa), followed by Proteus spp., with a prevalence of $7.8 \%$ (16.6\% of bacterial otitis externa) and Pseudomonas spp., with a prevalence of $3.9 \%$ ( $8.4 \%$ of bacterial otitis externa). Bacterial organisms play an important role in otic diseases as a secondary or perpetuating factor and are usually opportunistic (Greene, 1998; Jacobson, 2002). Bacteria isolated from cases of feline otitis externa include Staphylococcus, Pseudomonas, Escherichia, Proteus, Enterococcus, and Corynebacterium species (Carter and Chengappa, 1993; Jacobson, 2002; Hariharan et al., 2006; Qekwana et al., 2017; Kittl et al., 2018). Staphylococcus species were the most commonly isolated bacterial organisms from dogs and cats with otitis externa and Pseudomonas infection was prevalent in chronic-resistant cases (Jacobson, 2002; Hariharan et al., 2006), which is in accordance with the observations reported in this study.

Recently, many antibiotic-resistant bacterial strains have emerged (Hariharan et al., 2006; Gronthal et al., 2014; Qekwana et al., 2017). Therefore, an antimicrobial susceptibility assays are required to determine the susceptibility to extended antimicrobial classes and for monitoring this phenomenon.

Accordingly, our results revealed that bacterial organisms, which caused feline otitis externa, were most susceptible to norfloxacin and gentamicin when compared to other antimicrobials. These observations are in accordance with Hariharan et al. (2006), who noted that $\geq 70 \%$ of bacterial isolates of canine and feline origin were more susceptible to gentamicin and enrofloxacin and, more particularly, $90 \%$ of isolates were susceptible to gentamicin.

The present study showed that staphylococcal isolates were most susceptible to norfloxacin, followed by gentamicin and less susceptible to oxytetracycline, penicillin, and amoxicillin, but resistant to colistin. Hariharan et al. (2006) also reported that staphylococcal isolates of feline otitis externa were susceptible to gentamicin, enrofloxacin, and clavulanated amoxicillin, but more frequently resistant to penicillin and ampicillin.

Proteus isolates were also more susceptible to gentamicin and less susceptible to norfloxacin, oxytetracycline, and amoxicillin, but resistant to penicillin and colistin. Hariharan et al. (2006) and Jacobson (2002) similarly reported that Proteus isolates were more susceptible to enrofloxacin and gentamicin in cases of canine otitis externa. Our study also showed that Pseudomonas isolates were more susceptible to norfloxacin and gentamicin, and less susceptible to oxytetracycline and colistin, but resistant to amoxicillin and penicillin. Hariharan et al. (2006) and Jacobson (2002) also reported that Pseudomonas isolates were susceptible to gentamicin and polymyxin B, but more resistant to penicillin in canine otitis externa cases.

In conclusion, this is the first study to provide novel data on the status of feline otitis externa and antimicrobial susceptibility and determine the most common etiologies responsible for feline otitis externa in Tripoli, Libya. Otodectic mites and bacterial organisms constituted equally the most prevalent 
causes of otitis externa in affected cats. Ear mite $(O$. cynotis) infestation caused frequently severe bilateral otitis externa. Staphylococcus spp. was the most prevalent cause of feline otitis externa among bacterial organisms, followed by Proteus spp. and Pseudomonas spp.. Norfloxacin and gentamicin were the most effective antimicrobials against bacterial isolates.

\section{Conflict of interest}

The authors declare that there is no conflict of interest.

\section{Authors' contribution}

Omar Ellraiss examined the patients and collected the samples. Elfurgani Karim and Rabia Elmishri carried out the laboratory examination. Abdulnasser Altaeb contributed to consultation and revising the manuscript. Enass Duro carried out the statistical analysis of data. Emad Bennour and Murad Hiblu equally contributed to designing the study, interpreting the results, and writing the manuscript.

\section{Acknowledgment}

The authors would like to thank all colleagues at AlHelal Al-Azraq central veterinary clinic, particularly Dr. Abojala E. Ammar, Director of the clinic, Dr. Emaduldin A. Albdulkarim and Dr. Ekhlass H. Dakheil, for their cooperation and support.

\section{References}

Arisov, M.V., Indyuhova, E.N. and Arisova, G.B. 2020. The use of multicomponent ear drops in the treatment of otitis of various etiologies in animals. J. Adv. Vet. Anim. Res. 7, 115-126.

Bollez, A., de Rooster, H., Furcas, A. and Vandenabeele, S. 2018. Prevalence of external ear disorders in Belgian stray cats. J. Feline Med. Surg. 20, 149154.

Carter, G.R. and Chengappa, M.M. 1993. Microbial diseases. A veterinarian's guide to laboratory diagnosis. Iowa City, IA: Iowa State University Press.

Crespo, M.J., Abarca, M.L. and Cabanes, F.J. 2000. Otitis Externa Associated with Malassezia sympodialis in two cats. J. Clin. Microbiol. 38, 1263-1266.

Dion, W.M. and Speckmann, G. 1978. Canine otitis externa caused by the fungus Sporothrix schenkii. Can. Vet. J. 19,44-45.

dos Reis Gomes, A., Cabana, Â.L., da Gama Osório, L., Santin, R., Schuch, I.D., Serra, E.F., Nascente, P.S. and Araújo Meireles, M.C. 2014. First isolation of the Stephanoascus ciferrii in feline otitis in Brazil. Brazilian J. Microbiol. 45, 1101-1103.

Greene, C.E. 1998. Otitis externa. In Infectious diseases of the dog and cat, 2nd ed. Ed., C.E. Greene. Philadelphia, PA: W. B. Saunders, pp: 549-554.

Griffin, C.E. 1993. Otitis externa and otitis media. In Current veterinary dermatology: the science and art of therapy. Eds., Griffin, C.E., Kwochka, K.W. and MacDonald, J.M. St. Louis, MO: Mosby, pp: 245-262.
Gronthal, T., Moodley, A., Nykasenoja, S., Junnila, J., Guardabassi, L., Thomson, K. and Rantala, M. 2014. Large outbreak caused by Methicillin resistant Staphylococcus pseudintermedius ST71 in a finnish veterinary teaching hospital - from outbreak control to outbreak prevention. PLoS One. 9, e110084.

Hariharan, H., Coles, M., Poole, D., Lund, L. and Page, R. 2006. Update on antimicrobial susceptibilities of bacterial isolates from canine and feline otitis externa. Can. Vet. J. 47, 253-255.

Harvey, R.G. and Paterson, S. 2014. Medical management of ear disease. Otitis externa: an essential guide to diagnosis and treatment. Boca Raton, FL: CRC Press.

Jacobson, L.S. 2002. Diagnosis and medical treatment of otitis externa in the dog and cat. S. Afr. Vet. Ver. $73,162-170$.

Kennis, A. 2013. Feline otitis: diagnosis and treatment. Vet. Clin. Small Anim. 43, 51-56.

Kittl, S., Brodard, I., Rychener, L., Jores, J., Roosje, P. and Gobeli Brawand, S. 2018. Otitis in a cat associated with Corynebacterium provencense. BMC Vet. Res. 14, 200.

Markey, B., Leonard, F., Archambault, M., Cullinane, A. and Maguire, D. 2013. Clinical veterinary microbiology, 2nd ed. Chicago, IL: Mosby Elsevier.

Mascarenhas, M.B., Botelho, C.B., Martins Land Manier, B.S., Costa, T.S. and Fernandes, J.I. 2019. An unusual case of feline otitis externa due to sporotrichosis. JFMS Open Rep. 5, 2055116919840810.

Momota, Y., Yasuda, J., Ikezawa, M., Sasaki, J., Katayama, M., Tani, K., Miyabe, M., Onozawa, E., Azakami, D., Ishioka, K. and Sako, T. 2016. Proliferative and necrotizing otitis externa in a kitten: successful treatment with intralesional and topical corticosteroid therapy. J. Vet. Med. Sci.78, 1883-1885.

Moriello, K. 2013. Overview of otitis externa. Ear disorders. In MERCK veterinary manual. Available via https://www.merckvetmanual.com/eardisorders/otitis-externa/overview-of-otitis-externa (Accessed April 2020).

Nardoni, S., Ebani, V.V., Fratini, F., Mannella, R., Pinferi, G., Mancianti, F., Finotello, R. and Perrucci, S. 2014. Malassezia, mites and bacteria in the external ear canal of dogs and cats with otitis externa. Slov. Vet. Res. 51, 113-118.

Perego, R., Proverbio, D., Bagnagatti De Giorgi, G., Della Pepa, A. and Spada, E. 2014. Prevalence of otitis externa in stray cats in northern Italy. J. Feline Med. Surg. 16, 483-490.

Powell, M.B., Weisbroth, S.H., Roth, L. and Wilhelmsen, C. 1980. Reaginic hypersensitivity in Otodectes cynotis infestation of cats and mode of mite feeding. Am. J. Ve.t Res. 41, 877-882.

Qekwana, D.N., Sebola, D., Oguttu, J.W. and Odoi, A. 2017. Antimicrobial resistance patterns of 
Staphylococcus species isolated from cats presented at a veterinary academic hospital in South Africa. BMC Vet. Res. 13, 286.

Rosser, E.J. Jr. 2004. Causes of otitis externa. Vet. Clin. North. Am. Small. Anim. Pract. 34, 459-468.

Roy, J., Bédard, C. and Moreau, M. 2011. Treatment of feline otitis externa due to Otodectes cynotis and complicated by secondary bacterial and fungal infections with Oridermyl auricular ointment. Can. Vet. J. 52, 277-282.

Sotiraki, S.T., Koutinas, A.F., Leontides, L.S., Adamama-Moraitou, K.K. and Himonas, C.A. 2001. Factors affecting the frequency of ear canal and face infestation by Otodectes cynotis in the cat. Vet. Parasitol. 96, 309-315.

Shokri, H., Khosravi, A., Rad, M. and Jamshidi, S. 2010. Occurrence of Malassezia species in persian and domestic short hair cats with and without otitis externa. J. Vet. Med. Sci. 72, 293-296.

Topala, R., Burtan, I., Fantanaru, M., Ciobanu, S. and Burtan, L.C. 2007. Epidemiological studies of otitis externa at carnivores. Lucr. St. Med. Vet. Timisoara. 40, 647-651.

Tyler, S., Swales, N., Foster, A.P., Knowles, T.G. and Barnard, N. 2019. Otoscopy and aural cytological findings in a population of rescue cats and cases in a referral small animal hospital in England and Wales. J. Feline Med. Surg. 22, 1098612 X1983496.

Yang, C. and Huang, H. P. 2016. Evidence-based veterinary dermatology: a review of published studies of treatments for Otodectes cynotis (ear mite) infestation in cats. Vet. Dermatol. 27, 221-e56. 